\title{
Smartphone apps for improving medication adherence in hypertension: patients' perspectives
}

This article was published in the following Dove Press journal:

Patient Preference and Adherence

\author{
Eimear C Morrissey ${ }^{1,2}$ \\ Monica Casey ${ }^{3}$ \\ Liam G Glynn ${ }^{4}$ \\ Jane CWalsh ${ }^{2}$ \\ Gerard J Molloy' \\ 'Medication Adherence Across the \\ Lifespan Research Group, School \\ of Psychology, National University \\ of Ireland Galway, Galway, Ireland; \\ ${ }^{2}$ mHealth Research Group, School \\ of Psychology, National University \\ of Ireland Galway, Galway, Ireland; \\ ${ }^{3}$ School of Medicine, National \\ University of Ireland Galway, Galway, \\ Ireland; ${ }^{4}$ Graduate Entry Medical \\ School, University of Limerick, \\ Limerick, Ireland
}

Purpose: Digital interventions, such as smartphone applications (apps), are becoming an increasingly common way to support medication adherence and self-management in chronic conditions. It is important to investigate how patients feel about and engage with these technologies. The aim of this study was to explore patients' perspectives on smartphone apps to improve medication adherence in hypertension.

Methods: This was a qualitative study based in the West of Ireland. Twenty-four patients with hypertension were purposively sampled and engaged in focus groups. Thematic analysis on the data was carried out.

Results: Participants ranged in age from 50 to 83 years ( $M=65$ years) with an equal split between men and women. Three major themes were identified in relation to patients' perspectives on smartphone apps to improve medication adherence in hypertension: "development of digital competence," "rules of engagement," and "sustainability" of these technologies.

Conclusion: These data showed that patients can identify the benefits of a medication reminder and recognize that self-monitoring their blood pressure could be empowering in terms of their understanding of the condition and interactions with their general practitioners. However, the data also revealed that there are concerns about increasing health-related anxiety and doubts about the sustainability of this technology over time. This suggests that the current patient perspective of smartphone apps might be best characterized by "ambivalence."

Keywords: qualitative, high blood pressure, digital technology, self-management, adherence, focus groups, thematic analysis

\section{Introduction}

Hypertension is an important risk factor for cardiovascular and cerebrovascular events in both developed and developing countries. ${ }^{1}$ It is estimated that hypertension currently affects one billion people worldwide, ${ }^{2}$ and this number is expected to increase with population growth and aging. Therefore, this condition represents a global health challenge. $^{3}$

Blood pressure (BP) control through pharmacological treatment has led to substantial benefits in the prevention of morbidity and mortality from cardiovascular disease. ${ }^{4}$ A Cochrane review ${ }^{5}$ conducted for the assessment of all the trials of BP-lowering therapy found that these treatments reduced death, strokes, and heart attack. However, despite the efficacy of antihypertensive agents, there is a significant problem of nonadherence to these medications in those diagnosed with hypertension; ${ }^{6,7}$ therefore, the effectiveness of current treatment is limited.

As a largely asymptomatic disease, hypertension presents a challenge for appropriate adherence to treatment and engagement with self-care. ${ }^{8}$ High adherence (defined as a medication possession ratio of $80 \%-100 \%$ ) to hypertensive medications is associated
Correspondence: Eimear C Morrissey School of Psychology, National University of Ireland Galway, University Road, Galway H9IEV56, Ireland

Tel +l I 353876708518

Email e.morrissey6@nuigalway.ie 
with higher probability of BP control compared with those with medium or low levels of adherence. ${ }^{9}$ Evidence from a number of studies suggests that as many as $50 \%-80 \%$ of patients prescribed pharmacological antihypertensive therapy have low adherence to their treatment regimen, ${ }^{10}$ and this may be the most important cause of failure to achieve BP control. ${ }^{11}$

Interventions to enhance adherence to antihypertensives often involve self-monitoring of BP (eg, Hosseininasab et al, ${ }^{12}$ Marquez-Contrerase et al, ${ }^{13}$ and Margolius et $\mathrm{al}^{14}$ ) and contain medication reminders such as environmental prompts or cues (eg, Morrissey et $\mathrm{al}^{15}$ ). Evidence suggests that these methods have established efficacy to improve adherence. ${ }^{16-18}$ Digital health interventions, such as those that can be delivered via smartphone applications (apps) or connected wireless BP monitors, offer a new, scalable, and potentially cost-effective way to improve medication-taking behaviors. In the case of hypertension, they may provide a feasible method of supporting reminder strategies and selfmonitoring of BP, ${ }^{19}$ without overwhelming capacity within the health care system. However, uncertainties about the appropriate implementation of these technologies remain. ${ }^{20}$

A content analysis by Kumar et $\mathrm{al}^{21}$ focused on apps for hypertension management and found that these apps contained tools specifically for medication adherence (eg, pill reminders) and also performed a BP-tracking function through a wireless BP monitor. Green ${ }^{22}$ claimed that the emergence of these types of smartphone apps offers a new important strategy for patients and their families to be more actively involved in hypertension self-care. While these technologies may have the potential to support the clinical management and self-management of hypertension, there are also significant theory and evidence indicating that new tasks and technologies have the potential to create an undesirable burden ${ }^{23}$ for people with these conditions, and it remains unclear whether these technologies are feasible, acceptable, and usable in the context of self-management of hypertension. ${ }^{24}$ Therefore, it is useful to investigate how patients themselves feel about and engage with these types of apps in the context of one of the most common health conditions of older adulthood. The aim of this study was to explore patients' perspectives on smartphone apps to improve medication adherence in hypertension.

\section{Methods}

\section{Design}

A qualitative descriptive study was conducted. Discussion in the focus groups centered on usability and acceptability of an app to self-manage hypertension, as participants in in the focus group interacted with the app for the first time. The study is reported by using the consolidated criteria for reporting qualitative research checklist ${ }^{25}$ to ensure rigor in reporting how the study was conducted (see Table S1).

\section{Sample and recruitment}

Participants for the focus groups were recruited through Croí, a heart and stroke charity based in the West of Ireland, who advertised it through e-mail and social media channels. Hypertensive patients who were prescribed at least one antihypertensive medication were eligible to take part. Participants were sampled purposively to ensure adequate variation in age, sex, length of hypertension diagnosis and antihypertensive prescription, and experience with technology. Eight focus groups were held with 24 participants. All the participants provided written informed consent and received a $€ 20$ voucher for their participation.

In order to be responsive to and incorporate findings from the data as they emerged, an iterative approach was used. ${ }^{26}$ As it is common in qualitative sampling methodology, recruitment continued until data saturation was reached, and no new themes emerged. ${ }^{27}$ The focus groups were conducted in Croí House, a dedicated heart and stroke center for the West of Ireland.

\section{The app}

MiBP is a smartphone app for the self-management of hypertension. It is typical of current hypertension self-management apps in that it consists of two main aspects - the first is a reminder to take medication, and the second is home BP monitoring where the patient has a home BP monitor that is connected with the app via Bluetooth. The monitor sends the BP values to the app and produces a graph of BP measurements. Refer to Figure 1 for screenshots of the app.

\section{Data collection}

Eight focus groups were conducted in total. The focus groups comprised of 3-5 participants per group. The topic guide was developed by reviewing other qualitative research in the area, subsequently revised by the research team, and piloted with two hypertensive patients. This led to the final topic guide. The participants individually consented to the focus groups being conducted and recorded and to anonymous quotations being used.

\section{Data analysis}

The five stages of thematic analysis (namely familiarization, generation of codes, searching for themes, reviewing themes, 

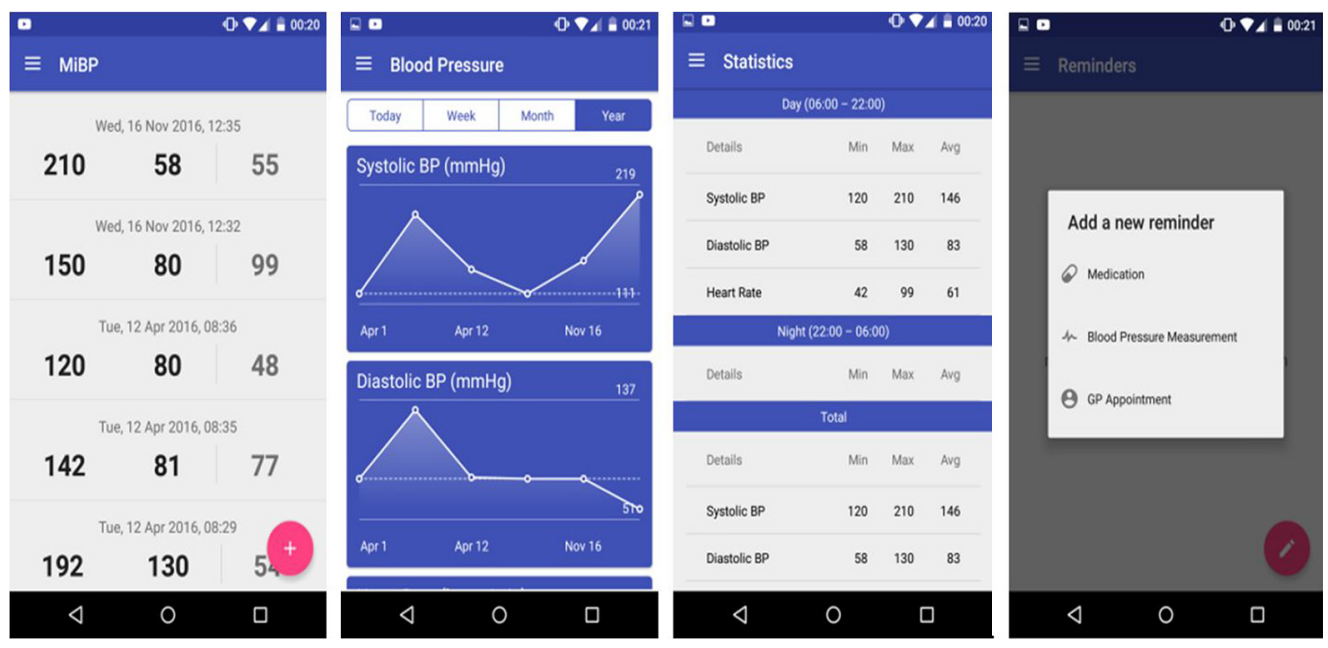

Figure I Screenshots of MiBP, showing the home screen, monitoring functions, and reminder function.

and defining themes) ${ }^{28}$ were followed. Coding was partially done by another researcher (MC) from a different professional background (nursing) to the main investigator (psychology) for intercoder reliability. ${ }^{29}$ To heighten reflexivity, four members of the research team (two health psychologists, a general practitioner [GP], and a nurse) joined with the lead researcher (a $\mathrm{PhD}$ candidate in health psychology) to review all the data and contribute to the thematic analysis. ${ }^{30} \mathrm{NVivo}$ (Version 11) was used to organize and code the transcripts to facilitate the analysis and comparison of relationships between the codes. ${ }^{31}$

\section{Ethical approval}

Ethical approval for this study was sought and obtained from Galway University Hospitals Clinical Research Ethics Committee (Reference: CA1497).

\section{Results}

Table 1 shows the characteristics of the participants. Three main themes were identified in the data: development of digital competence, rules of engagement, and sustainability and maintenance.

\section{Development of digital competence}

The theme of "development of digital competence" refers to the pathway to becoming familiar and comfortable with using technology to manage hypertension. The participants in the focus groups varied in the extent to which they had developed (or desired to develop) digital competence. This ranged from not having any interest in engaging with the technology, to be fully competent and confident in its use.

Several participants said that they were not interested in using a smartphone app for hypertension management and had no desire to become digitally competent. Many of them felt that they had adequate systems already in place - both to monitor their BP levels and to remember to take their medication.

I wouldn't see myself using it [the app] at the moment. At the moment I have an old notebook beside the what not [BP monitor] and if I think I need to record something I'll stick it into it and then if I'm looking for a trend I'll just scan down the notebook. [Focus group 3, male (65 years)]

Table I Participant characteristics

\begin{tabular}{ll}
\hline Characteristics & \\
\hline Mean age, years (range) & $65(50-83)$ \\
Gender, $\mathrm{n}$ & \\
$\quad$ Male & 12 \\
$\quad$ Female & 12 \\
Education, $\mathrm{n}$ & \\
$\quad$ Primary & 0 \\
$\quad$ Secondary & 10 \\
$\quad$ Third level & 14 \\
Employment, $\mathrm{n}$ & \\
$\quad$ Full-time & 5 \\
Part-time & 4 \\
$\quad$ Retired & 15 \\
Marital status, $\mathrm{n}$ & \\
$\quad$ Married & 19 \\
Single & 5 \\
Location, $\mathrm{n}$ & \\
$\quad$ Urban & 16 \\
$\quad$ Rural & 8 \\
Health insurance (\%) & 75 \\
Mean length of time since diagnosis, years (range) & $12(\mathrm{I}-39)$ \\
Mean length of time since antihypertensive prescription, & $1 \mathrm{II}(\mathrm{I}-35)$ \\
years (range) & \\
Mean amount of antihypertensive medications, $\mathrm{n}$ (range) & $2(\mathrm{I}-4)$ \\
Mean amount of other medications, $\mathrm{n}$ (range) & $\mathrm{I}(0-5)$ \\
Smartphone user (\%) & 66 \\
Health app user (\%) & 8 \\
\hline Note $\mathrm{n}-24$ &
\end{tabular}

Note: $\mathrm{n}=24$. 
I just think it's like everything, it becomes a habit. I don't think you need a piece of technology to remind you to take a tablet because if you are taking ... I mean do you need technology to remind you to have breakfast or brush your teeth or have a shower? The answer is no. I think if you are used to doing this as part of a routine I just think in general it just all fits in together. [Focus group 5, female (66 years)]

Others felt that while many of their current systems were not perfect, using the medication reminder function of the app would mean that they were "giving in" to technology. One participant outlined how this discomfort was preventing him from engaging with the app.

I'm kind of afraid in a way to use it because I kind of look at that maybe I might be admitting that the memory isn't as good as it used to be ... I kind of like to think that I'd have no problem, I'll remember it, I will remember this or to do it ... [Focus group 5, male (50 years)]

While some of these patients were sure that they would never use the app, others felt, while they were not currently interested, that they might use it in the future. They could see the benefit of the app in supporting their hypertension self-management but did not identify as being hypertensive enough to currently need it.

When I saw it I thought that I'd never use it and I think now after listening to everybody discussing things I'm probably very lucky that I'm on mild medication and I thought well if I was in the severe end of the spectrum it would be excellent to have. Maybe if I disimproved or something like that I could definitely see or if I ended up living on my own which hopefully is not going to be likely. [Focus group 1, female (61 years)]

Those who were interested in using the app, but did not feel comfortable with operating a smartphone to the level required, were further along the pathway to digital competence. A need for instruction and practice was expressed by several participants.

It's good but you'd need it to be explained. I think initially if you get one lesson. If it's explained to you and if you could get one follow up I think I would use it then. [Focus group 2, female (82 years)]

Some participants valued the outputs of the app, such as graphs of BP readings, and cited these as a motivation to become familiar with the technology. They felt empowered by these data and felt that this was an encouragement to continue using the app and become familiar with the different functions.

Using it [the app] gives you great confidence. [P1 of focus group 2: female (65 years)]

It would because it's your own health and there's nothing more important. [P2 of focus group 2: female (82 years)]

Yeah, it makes you feel good. [P3 of focus group 2: female (65 years)]

\section{Rules of engagement}

The second theme was rules of engagement. This centered on participants' engagement and disengagement with the different functions of the app and their motivations to do so.

Very few of the participants had been using a smartphone app to manage their hypertension before this study. Most of them were not engaging with this type of technology because they were not aware of it. Lack of knowledge about apps for hypertension management was frequently spoken about in the focus groups.

For those who were already using a BP monitor at home, there were very mixed opinions about the amount of time someone should spend measuring and monitoring BP. This dissonance was found in some participants who were extremely engaged and those who were less interested. None of the participants expressed any knowledge of the official recommendations for home BP monitoring.

Yeah, I bought a machine straight away. I was testing myself three times a day and before I'd see the consultant. I'd check myself three times a day and then I'd give him an excel sheet with all my readings on it. I'm too young like.

[Focus group 1, male (65 years)]

Sometimes I'd use the monitor at home ... It holds I think maybe 15 in memory but I never bother with the memory. If I'm hitting my target range, forget about it. If I'm outside the target range, take it again tomorrow and see if there's something. [Focus group 7, male (61 years)]

Some participants expressed a reluctance to engage with the home BP monitor aspect of the app. There was a sense of ambiguity around what to do with the readings, particularly if they were high. This led some participants to consider it to be unnecessarily anxiety provoking, possibly leading to needless concern and doctor visits.

I think it could make you a hypochondriac at times. That something could be wrong and you go running off to the doctor ... [Focus group 3, female (71 years)] 
However, for others, the home BP monitor aspect of the app was a big motivation for engagement. Some participants really liked the idea of having their BP reading presented visually and were particularly impressed with being able to view a graph of their BP readings over time.

The presentation gives you a constant read and you can always check back without ... Just to see how things are. You could look back at what it was and you can see between November and February how you were getting on and you get a fair idea that overall you have been very well balanced for the last three or four months. [Focus group 7, male ( 83 years)]

Feeling empowered by being able to follow and track their BP readings, the participants also felt that the app could empower them when visiting a doctor.

The big advantage I have with this app is when I go to the consultant I can hand him the phone ... Because I know with the consultant the minute I walk out the door he's forgotten I was there and there's somebody else in after me and the poor man, he's only human he can only remember so much or whatever, he looks at the file and tries to ... But I know that I go in in a year or six months later he has to say, Who's your man again? Whereas when I give him the information there and say, that's how I've been doing for the last month for example. It doesn't lie and as I said I'm feeling I'm getting more value for my money basically because you are not getting ... You are not getting the thing the thing they talk about, this White Coat Hypertension because you are taking it at home on your kitchen table.

[Focus group 1, male (65 years)]

This feeling of gaining some control over their health and health care drove enthusiasm for engagement with the app. The reminder aspect was also featured as a motivation, particularly for participants who sometimes were out of routine.

I think it would be good for me because since I'm a paramedic. After I get off working 12 hours at night that's the last thing on my mind is kind of taking medication, I'm just looking for a bed to be honest. So it would be very helpful. [Focus group 5, male (53 years)]

It's more the reminder for me and to remind me not to leave them behind me because I have two daughters living in different parts of the country so when I go to them I sometimes leave the medication in an area and then I could come back without it easily enough so if I had the reminder at ten I'd take the tablets and I'd put them away then.
Put them into my bag or whatever. [Focus group 6, female (65 years)]

\section{Sustainability}

The final theme of sustainability refers to the participants' thoughts and feelings about maintaining both hypertension self-management and the use of the app in the long term.

Some participants were not comfortable with using the app in the long term without their doctors' approval. They felt that in order to keep engaging with the app, their doctor would also have to be involved. The app-forming part of their doctor-patient relationship encouraged sustainability.

There is another question, would it be acceptable to your doctor when you'd go in and to have your blood pressure taken and you introduced your app? Would he be okay with that? [P1 of focus group 4: male (79 years)]

I suppose that depends on the doctor. Some of the older doctors may not be. [P2 of focus group 4: male (78 years)]

So do you think if you went to the doctor's office and they thought the app was a good idea, would you keep using it then? [Moderator of focus group 4]

Oh yes. [P1 of focus group 4: male (79 years)]

Yes. Then I'd have no problem. [P2 of focus group 4: male (78 years)]

Similarly, some liked the idea of the app being expanded to include the patients' medical history. They felt that this would be an advantage in any situation that required medical care and would be a good incentive to keep using it.

Overall I found it interesting. Like I said once if it can be expanded to include the patient's history in case of emergency or where it would be recognised in a hospital as the voice where one's personal medical history would be on. [Focus group 4, male (79 years)]

Others raised concerns about data regulations. One participant felt that in order to store his personal medical or BP information on an app over a period of time, he would need to know more about what kind of privacy standards the app was complying with.

I'd probably use the blood pressure monitoring part but there would have to be better stringent kind of regulations and I'd want to be made aware of them. [Focus group 6, male (57 years)]

A strong barrier to sustainability was the home BP monitoring equipment that is required to use the app correctly. Some thought that the cost of buying the equipment 
was too high, and others felt that having to carry extra equipment around was too awkward and was not worth the inconvenience.

I just think like not everybody who has the App would want to invest in buying a blood pressure monitor ... [Focus group 8 , female (64 years)]

A common fear that was expressed was that constant reminders from the app would become annoying over time, leading to disengagement. Some participants had experienced this in the past with other health-related apps. This "nagging" had led several participants to discontinue the use or delete the app.

I have downloaded the BBC health programme but it was nagging me so much particularly in the evenings. For the last year I couldn't do anything with the knee so I said, I'm getting tired of being nagged so I haven't used it much. [Focus group 6, male (50 years)]

Finally, the participants felt that this app would be very sustainable in the future. They spoke of how the younger generations are using smartphone apps for many different purposes and so would be happy to use an app for hypertension self-management in the long term.

It's the same thing basically but this is just using technology and I suppose going forward ... My mother wouldn't be able to use this because she didn't grow up with it but I can see my own kids in their 30's, the first thing they go to if you ask them, Is it going to rain tomorrow, The first thing they go to is the phone. [P2 of focus group 1: female (61 years)]

They don't buy the paper anymore they just look at the phone. [P1 of focus group 1: male (65 years)]

So in 15 years time people will want this there's no doubt about it or anything similar. It's good. [P2 of focus group 1: female (61 years)]

\section{Discussion}

\section{Summary}

The data from these focus groups provide valuable insights into hypertensive patients' perspectives on using smartphone apps to manage hypertension. The three major themes were identified: "development of digital competence," "rules of engagement," and "sustainability." Participants were at varying stages of digital competence - from having no interest in using technology to help with their self-management of hypertension to being extremely confident with the use of these kinds of smartphone apps. In those who were engaging with these apps, there was a dissonance in attitudes.
Some were extremely motivated and felt empowered by the additional health data that the app was providing, whereas others expressed strong concerns about these data, leading to increases in health anxiety. In terms of sustainability, some concerns were raised about using these types of apps in the long term, but this was offset by a confidence that the younger generations would be very likely to engage with them fully in the future.

\section{Comparison with existing literature}

The findings of this study support previous research in the field of using self-management technology, such as smartphone apps, to manage hypertension. A similar qualitative study $^{24}$ on a mobile phone-based system to support the management of hypertension found that some of the participants had difficulties with the mobile platform of the system. This is reflective of our theme of "development of digital competence." It is possible that this is because hypertensive patients being an older cohort of the population who are less likely to engage with newer information and communication technologies compared with younger people. ${ }^{32}$

A recent meta-ethnography of digital interventions for the self-management of chronic physical health conditions ${ }^{33}$ concluded that patients who were engaging with these digital interventions felt reassured by the insight into their health that these tools provided. Specifically, in terms of hypertension, a recent thematic synthesis of patient and providers' perspectives on self-monitoring of $\mathrm{BP}^{34}$ inferred that, for patients, self-monitoring was seen as a balance between reassurance and anxiety. This is reflected in our data, where some patients spoke of being motivated by the extra data and others were concerned about feelings of anxiety when readings were high. Fletcher et $\mathrm{al}^{34}$ suggested that this uncertainty could be reduced by the patients and GPs working together around how to interpret home BP values, how to adjust for home-clinic values, and particularly what values patients should get concerned at and when to act. This desire to work together with the GP was seen in the current data under the theme of sustainability.

Jolles et $\mathrm{al}^{35}$ emphasized the importance of effective communication in a successful encounter between hypertensive patients and their GPs. Participants in this study felt that using the smartphone app could enhance their communication with their GPs. This is reflected throughout the literature, with participants in the study by Hallberg et $\mathrm{al}^{24}$ reporting that being able to visualize their BP values led to a better discussion at the consultation. This is in line with an empirical study by Ruckenstein ${ }^{36}$ which posits that making health data visible can add meaning to activities that can have an effect on these data. 
Making an asymptomatic condition like hypertension more tangible using imagery that the patient can make sense of is an approach that has been used to influence health-relevant behavior in other health and illness contexts. ${ }^{37}$

Some studies involving GPs ${ }^{20,38}$ have found reluctance in them to engage with these technologies due to fears around augmented workload and increased patient anxiety. Participants in the present study were very conscious of their GPs' workload but saw this app as an opportunity to decrease it, as it meant that the GP could immediately be presented with up-to-date BP data. Bengtsson et $\mathrm{al}^{39}$ suggested that when using digital interventions, GPs and patients need to understand each other's needs and circumstances and should concordantly agree on a treatment and treatment goal.

\section{Strengths and weaknesses}

This study provided novel and timely data on hypertensive patients' perspectives of using smartphone apps to support self-management. Focus groups were an appropriate methodology to use for discussion about the usability of the app as they have high ecological validity and facilitate gathering of new knowledge around issues little is known about. ${ }^{40}$

The multidisciplinary research team coming together to review the data increased reflexivity, but it is possible to also view this as another limitation as the team may have taken a different emphasis to that of an independent observer. These findings are consistent with others in the field (eg, Morton et $\mathrm{al}^{33}$ ) suggesting external validity. However, the sample was relatively small and from one geographical location and so may not fully encapsulate the perspectives of all patients with hypertension. In addition, while hypertension is typical of a chronic disease, it is possible that some of the challenges of other common chronic conditions such as diabetes or asthma were not captured in the data as the sample was limited to hypertensive patients.

\section{Implications for research and practice}

This study recognized that while many of hypertensive patients are willing and eager to engage with smartphone apps to manage their hypertension, it is weighed against some concerns. Future research and development work should focus on how to make this type of intervention sustainable (eg, Serrano et $\mathrm{al}^{41}$ ), as many participants expressed doubts about maintaining app use over time. The limitations of technology to drive behavior change and the need to design long-term engagement strategies into these kinds of technology are well recognized in this literature as sustainability is often identified as a key challenge. ${ }^{42,43}$
Patients engaging with these types of technologies may have the potential to increase the amounts of BP data available to GPs. This may lead to patients engaging in their health care in a more informed and patient-centered manner. Mudge et $\mathrm{al}^{44}$ noted in a recent meta-synthesis that this shift in the power balance can be uncomfortable for some clinicians. Some strategies found to be helpful in this process of change included peer support, practicing reciprocity in communication style, and self-reflection. The adoption of these types of technologies would also be easier if it was supported in a national eHealth infrastructure that is integrated into public health systems; however, this is yet to be achieved in most international contexts including the present study context.

The participants did express some reluctance around health care apps in general, due to fears of misinformation or increases in anxiety. There is also evidence to suggest that commercially available apps for medication adherence have not benefited from developments in the behavioral science of behavior change as they often have limited identifiable active ingredients in the form of recognizable behavior change techniques. ${ }^{45}$ The National Health Service Health Apps library in the UK provides patients with access to a list of endorsed apps, and these data highlight a need for a similar platform to be created by a health regulation body in Ireland and perhaps other contexts, given the potential uncertainty about the benefits and harms of these technologies.

\section{Conclusion}

Overall, the patients were divided in their views on using a smartphone app to self-manage their hypertension. Many could see the benefit of a medication reminder and felt that self-monitoring their BP would be empowering in terms of their understanding of the condition and interactions with their GPs. However, there were concerns about increasing health-related anxiety and doubts about the sustainability of this technology over time.

\section{Acknowledgment}

The authors would like to acknowledge and thank all the participants.

\section{Disclosure}

The authors report no conflicts of interest in this work.

\section{References}

1. Kearney PM, Whelton M, Reynolds K, Muntner P, Whelton PK, He J. Global burden of hypertension: analysis of worldwide data. Lancet 2005;365(9455):217-223.

2. Alwan A. Global Status Report on Noncommunicable Diseases 2010 Geneva, Switzerland: World Health Organization; 2011. 
3. Forouzanfar MH, Liu P, Roth GA. Global burden of hypertension and systolic blood pressure of at least 110 to $115 \mathrm{~mm} \mathrm{hg}, 1990-2015$. JAMA. 2017:317(2):165-182.

4. Wright JM, Musini VM. First-line drugs for hypertension. Cochrane Database Syst Rev. 2009;(3):CD001841.

5. Musini VM, Tejani AM, Bassett K, Wright JM. Pharmacotherapy for hypertension in the elderly. Cochrane Database Syst Rev. 2009; (4):CD000028.

6. Durand H, Hayes P, Morrissey EC, et al. Medication adherence among patients with apparent treatment-resistant hypertension: systematic review and meta-analysis. $J$ Hypertens. 2017;35(12):2346-2357.

7. Vrijens B, Antoniou S, Burnier M, de la Sierra A, Volpe M. Current situation of medication adherence in hypertension. Front Pharmacol. 2017;8:100.

8. Holt EW, Rung AL, Leon KA, Firestein C, Krousel-Wood MA. Medication adherence in older adults: a qualitative study. Educ Gerontol. 2014;40(3):198-211.

9. Bramley TJ, Gerbino PP, Nightengale BS, Frech-Tamas F. Relationship of blood pressure control to adherence with antihypertensive monotherapy in 13 managed care organizations. J Manag Care Pharm. 2006;12(3):239-245.

10. Elliott WJ. What factors contribute to the inadequate control of elevated blood pressure? J Clin Hypertens (Greenwich). 2008;10(1 Suppl 1): 20-26.

11. Sabaté E. Adherence to Long-term Therapies: Evidence for Action. Geneva, Switzerland: World Health Organization; 2003.

12. Hosseininasab M, Jahangard-Rafsanjani Z, Mohagheghi A, et al. Self-monitoring of blood pressure for improving adherence to antihypertensive medicines and blood pressure control: a randomized controlled trial. Am J Hypertens. 2014;27(11):1339-1345.

13. Marquez-Contreras E, Martell-Claros N, Gil-Guillen V, et al. Efficacy of a home blood pressure monitoring programme on therapeutic compliance in hypertension: the EAPACUM-HTA study. J Hypertens. 2006;24(1):169-175.

14. Margolius D, Bodenheimer T, Bennett $\mathrm{H}$, et al. Health coaching to improve hypertension treatment in a low-income, minority population. Ann Fam Med. 2012;10(3):199-205.

15. Morrissey EC, Durand H, Nieuwlaat R, et al. Effectiveness and content analysis of interventions to enhance medication adherence and blood pressure control in hypertension: a systematic review and meta-analysis. Psychol Health. 2017;32(10):1195-1232.

16. Fletcher BR, Hartmann-Boyce J, Hinton L, McManus RJ. The effect of self-monitoring of blood pressure on medication adherence and lifestyle factors: a systematic review and meta-analysis. Am J Hypertens. 2015;28(10):1209-1221.

17. Glynn LG, Murphy AW, Smith SM, Schroeder K, Fahey T. Selfmonitoring and other non-pharmacological interventions to improve the management of hypertension in primary care: a systematic review. Br J Gen Pract. 2010;60(581):e476-e488.

18. Patel S, Jacobus-Kantor L, Marshall L, et al. Mobilizing your medications: an automated medication reminder application for mobile phones and hypertension medication adherence in a high-risk urban population. J Diabetes Sci Technol. 2013;7(3):630-639.

19. Band R, Bradbury K, Morton K, et al. Intervention planning for a digital intervention for self-management of hypertension: a theory-, evidence- and person-based approach. Implement Sci. 2017;12(1):25.

20. Morrissey EC, Glynn LG, Casey M, Walsh JC, Molloy GJ. New selfmanagement technologies for the treatment of hypertension: general practitioners' perspectives. Fam Pract. Epub 2017 Oct 27.

21. Kumar N, Khunger M, Gupta A, Garg N. A content analysis of smartphone-based applications for hypertension management. $J \mathrm{Am}$ Soc Hypertens. 2015;9(2):130-136.

22. Green BB. BP here, there, and everywhere - mobile health applications (apps) and hypertension care. J Am Soc Hypertens. 2015;9(2):137-139.
23. May CR, Eton DT, Boehmer K, et al. Rethinking the patient: using Burden of Treatment Theory to understand the changing dynamics of illness. BMC Health Ser Res. 2014;14:281.

24. Hallberg I, Ranerup A, Kjellgren K. Supporting the self-management of hypertension: patients' experiences of using a mobile phone-based system. J Hum Hypertens. 2016;30(2):141-146.

25. Tong A, Sainsbury P, Craig J. Consolidated criteria for reporting qualitative research (COREQ): a 32-item checklist for interviews and focus groups. Int J Qual Health Care. 2007;19(6):349-357.

26. Ziebland S, McPherson A. Making sense of qualitative data analysis: an introduction with illustrations from DIPEx (personal experiences of health and illness). Med Educ. 2006;40(5):405-414.

27. Glaser BG, Strauss AL, Strutzel E. The discovery of grounded theory; strategies for qualitative research. Nurs Res. 1968;17(4):364.

28. Braun V, Clarke V. Using thematic analysis in psychology. Qual Res Psychol. 2006;3(2):77-101.

29. Pope C, Ziebland S, Mays N. Qualitative research in health care. Analysing qualitative data. BMJ. 2000;320(7227):114-116.

30. Richards L. Handling Qualitative Data: A Practical Guide. London: Sage; 2014

31. Pitney W, Parker J. Qualitative Research in Physical Activity and the Health Professions. Champaign, IL: Human Kinetics; 2009.

32. Heart T, Kalderon E. Older adults: are they ready to adopt health-related ICT? Int J Med Inform. 2013;82(11):e209-e231.

33. Morton K, Dennison L, May C, et al. Using digital interventions for self-management of chronic physical health conditions: a metaethnography review of published studies. Patient Educ Couns. 2017; 100(4):616-635.

34. Fletcher BR, Hinton L, Hartmann-Boyce J, Roberts NW, Bobrovitz N, McManus RJ. Self-monitoring blood pressure in hypertension, patient and provider perspectives: a systematic review and thematic synthesis. Patient Educ Couns. 2016;99(2):210-219.

35. Jolles EP, Clark AM, Braam B. Getting the message across: opportunities and obstacles in effective communication in hypertension care. J Hyperten. 2012;30(8):1500-1510.

36. Ruckenstein M. Visualized and interacted life: personal analytics and engagements with data doubles. Societies. 2014;4(1):68-84.

37. Williams B, Cameron L. Images in health care: potential and problems. $J$ Health Serv Res Policy. 2009;14(4):251-254.

38. Bradbury K, Morton K, Band R, et al. Understanding how primary care practitioners perceive an online intervention for the management of hypertension. BMC Med Inform Decis Mak. 2017;17(1):5.

39. Bengtsson U, Kasperowski D, Ring L, Kjellgren K. Developing an interactive mobile phone self-report system for self-management of hypertension. Part 1: patient and professional perspectives. Blood Press. 2014;23(5):288-295.

40. Braun V, Clarke V. Successful Qualitative Research: A Practical Guide for Beginners. London: Sage; 2013.

41. Serrano KJ, Coa KI, Yu M, Wolff-Hughes DL, Atienza AA. Characterizing user engagement with health app data: a data mining approach. Transl Behav Med. 2017;7(2):277-285.

42. Donkin L, Christensen H, Naismith LS, Neal B, Hickie BI, Glozier N. A Systematic Review of the Impact of Adherence on the Effectiveness of e-Therapies. J Med Internet Res. 2011;13(3):e52.

43. Alkhaldi G, Hamilton LF, Lau R, Webster R, Michie S, Murray E. The effectiveness of prompts to promote engagement with digital interventions: a systematic review. J Med Internet Res. 2016;18(1):e6.

44. Mudge S, Kayes N, McPherson K. Who is in control? Clinicians' view on their role in self-management approaches: a qualitative metasynthesis. BMJ Open. 2015;5(5):e007413.

45. Morrissey EC, Corbett TK, Walsh JC, Molloy GJ. Behavior change techniques in apps for medication adherence: a content analysis. Am J Prev Med. 2016;50(5):e143-e146. 


\section{Supplementary material}

Table SI COREQ checklist

\begin{tabular}{|c|c|}
\hline Item & Description \\
\hline \multicolumn{2}{|l|}{$\begin{array}{l}\text { Domain I: research team and } \\
\text { reflexivity }\end{array}$} \\
\hline \multicolumn{2}{|l|}{ Personal characteristics } \\
\hline I. Interviewer/facilitator & One author (ECM) conducted the focus groups \\
\hline 2. Credentials & $\mathrm{BA}, \mathrm{MSc}$ \\
\hline 3. Occupation & PhD candidate \\
\hline 4. Gender & Female \\
\hline 5. Experience and training & Trained in qualitative methods and design, experience in conducting focus groups. \\
\hline \multicolumn{2}{|l|}{ Relationship with participants } \\
\hline 6. Relationship established & $\begin{array}{l}\text { Potential participants contacted ECM via e-mail or telephone to discuss arrangements for the focus } \\
\text { groups. Otherwise, participants had no relationship with the researcher. }\end{array}$ \\
\hline $\begin{array}{l}\text { 7. Participant knowledge of the } \\
\text { interviewer }\end{array}$ & $\begin{array}{l}\text { Participants were informed that the researcher was conducting a } \mathrm{PhD} \text { in the area of digital interventions } \\
\text { for hypertension, and her goal was to understand hypertensive patients' perspectives on this. }\end{array}$ \\
\hline 8. Interviewer characteristics & $\begin{array}{l}\text { The researcher was closely engaged in the research process and therefore unable to avoid personal } \\
\text { bias. This research sought to inform the content of an intervention. }\end{array}$ \\
\hline
\end{tabular}

Theoretical framework

9. Methodological orientation and theory

Participant selection

10. Sampling

II. Method of approach

12. Sample size

13. Nonparticipation

Setting

14. Setting of data collection

15. Presence of nonparticipants

16. Description of sample

Data collection

17. Interview guide

18. Repeat interviews

19. Audio/visual recording

20. Field notes

21. Duration

22. Data saturation

Thematic analysis was used in this study. An inductive approach was adopted.

Patients with hypertension in the West of Ireland were sampled purposively.

From October to November 2016, Croí (a cardiac health charity) advertised the study through e-mail and social media channels.

There were 24 participants in the study.

All the participants who agreed on a date and a time took part in a focus group.

Data were collected at Croí House, a dedicated heart and stroke center for the West of Ireland. No nonparticipants were present.

The characteristics of the sample are provided in Table I.

The focus group schedule was developed by reviewing other qualitative research in the area. It was then reviewed by the research team and piloted on two patients with hypertension.

No repeat interviews were carried out.

Audio recording was used to collect the data.

Field notes were made during and after the focus groups.

Each of the focus groups lasted $\sim$ h hour.

The researchers decided that data saturation had been achieved after the 8 th focus group. The transcripts were reviewed as soon as possible after each focus group. Saturation was achieved as no further additional new information began to emerge. It was agreed that the addition of new codes was unlikely after the 8 th focus group.

23. Transcripts returned

Domain 3: analysis and findings Data analysis

24. Number of data coders

25. Description of the coding tree

Transcripts were not returned to participants for comment and/or correction.

Two data coders (ECM and MC) coded the data.

Open coding was first performed. This consisted of transcripts being read thoroughly and sections of text being assigned to descriptive codes. Content of the transcripts was constantly compared with codes that were already established. After forming the codes, they were grouped into categories, which were then grouped into themes.

26. Derivation of themes

All five members of the research team came together to review all the data and contribute to the thematic analysis.

27. Software

28. Participant checking

Data were managed using NVivo Version II.

Participants did not provide feedback on the findings.

(Continued) 
Table SI (Continued)

\begin{tabular}{|c|c|}
\hline Item & Description \\
\hline \multicolumn{2}{|l|}{ Reporting } \\
\hline 29. Quotations presented & $\begin{array}{l}\text { Participant quotations are presented to illustrate the themes/findings. Each quotation is identified using } \\
\text { the participants' age and gender. }\end{array}$ \\
\hline 30. Data and findings consistent & $\begin{array}{l}\text { There is consistency between the data presented and the findings. The unit of analyses was the } \\
\text { theme rather than the prevalence or frequency of statements. Some statements of quantification are } \\
\text { included (eg, statements such as often and sometimes), but do not always aim at providing estimates of } \\
\text { prevalence. }\end{array}$ \\
\hline 31. Clarity of major themes & $\begin{array}{l}\text { Codes identified in the open coding stage were discussed by two study authors until consensus was } \\
\text { reached. All major themes are clearly presented in the findings. }\end{array}$ \\
\hline 32. Clarity of minor themes & No minor themes were present. \\
\hline
\end{tabular}

Abbreviation: COREQ, consolidated criteria for reporting qualitative research.

\section{Publish your work in this journal}

Patient Preference and Adherence is an international, peer-reviewed, open access journal that focuses on the growing importance of patient preference and adherence throughout the therapeutic continuum. Patient satisfaction, acceptability, quality of life, compliance, persistence and their role in developing new therapeutic modalities and compounds to optimize clinical outcomes for existing disease states are major areas of interest for the journal. This journal has been accepted for indexing on PubMed Central. The manuscript management system is completely online and includes a very quick and fair peer-review system, which is all easy to use. Visit http://www dovepress.com/testimonials.php to read real quotes from published authors.

Submit your manuscript here: http://www.dovepress.com/patient-preference-and-adherence-journal 